\title{
Optimized assay for the quantification of histidine kinase autophosphorylation
}

Takahiro B. Ueno ${ }^{1}$, Roger A. Johnson ${ }^{2}$, Elizabeth M. Boon ${ }^{1 *}$

${ }^{1}$ Department of Chemistry, Stony Brook University, Stony Brook, NY 11794-3400.

${ }^{2}$ Department of Physiology and Biophysics, Stony Brook University, Stony Brook, NY 117948661.

*Corresponding Author

Department of Chemistry, Stony Brook University, Stony Brook, NY 11794-3400. Telephone: (631) 632-7945. Fax: (631)632- 7960. E-mail: elizabeth.boon@stonybrook.edu.

(C) 2016. This manuscript version is made available under the Elsevier user license http://www.elsevier.com/open-access/userlicense/1.0/ 


\begin{abstract}
Although two-component signaling systems, comprising a sensory histidine kinase and a response regulator, are a primary means by which bacteria detect and respond to environmental stimuli, they are poorly characterized. Here we report optimized conditions for detecting histidine phosphorylation using a facile medium-throughput filter paper-binding assay. Employing this assay we report the kinetic parameters of previously uncharacterized histidine kinases from Vibrio haveyi, Vibrio parahaemolytius, Shewanella oneidensis, and Legionella pneumophila. In characterizing these kinases, we effectively double the number of kinetically characterized histidine kinases that have been reported in the literature.
\end{abstract}

\title{
KEYWORDS
}

Histidine kinase, TCS, two-component signaling, His-Asp phosphorelay, phospho-His, autophosphorylation, filter binding assay, autoradiography.

\section{INTRODUCTION}

Two-component signaling (TCS) systems are a predominant mechanism for stimulus response in bacteria $[1,2,3,4]$. TCS consists of a sensor histidine kinase (HK) and a response regulator (RR) [5]. The variable sensor domain of the $\mathrm{HK}$ is responsible for detecting a stimulus, which results in a change in the phosphorylation state of the HK. The signal is relayed downstream by means of phosphoryl transfer from the HK histidine to an aspartic acid in the receiver domain of the RR. The activated RR then elicits a response to the initial stimulus [6,7]. Many TCS systems deviate from this canonical system, however. In three-component systems, an accessory protein that detects a signal and regulates $\mathrm{HK}$ autophosphorylation in trans replaces the HK sensor domain 
[8,9]. In a hybrid TCS, the HK has a receiver domain, thus a His-to-Asp phosphotransfer takes place within the hybrid $\mathrm{HK}$, and then a histidine-containing phosphotransfer protein (Hpt) is required to relay the signaling phosphate from the HK to the appropriate RR in two additional phosphotransfer steps $[10,11,12]$. TCS is widely prevalent in bacteria; bacteria encode HKs capable of detecting a wide range of environmental stimuli that regulate biological functions essential for survival $[13,14,15]$.

Most in vitro TCS studies analyze basal HK autophosphorylation rates, phosphotransfer, and changes in these rates in response to environmental stimuli using $\left[\gamma_{-}{ }^{32} \mathrm{P}\right]-\mathrm{ATP}$ as the HK substrate and analysis of phosphorylation by polyacrylamide gel electrophoresis (PAGE) followed by autoradiography $[16,17]$. Although these PAGE-based assays are labor intensive, time-consuming, and have limited sample capacities, they remain the primary means for analysis of phosphorylated His (pHis) $[18,19,20]$. In part this is due to the inherent lability of pHis $[21,22,23,24]$, which hinders the application of techniques widely used for analysis of phosphorylated serine, threonine, and tyrosine residues [25]. Although several alternative analysis methods have been proposed to overcome the instability of pHis [26,27], each is nonetheless a PAGE-based assay. Here we report a carefully optimized filter paper-binding assay to determine the kinetic parameters of several previously uncharacterized HKs, nearly doubling the total number of kinetically characterized HKs $[18,19,20,28,29,30]$.

\section{MATERIALS AND METHODS}

Unless otherwise noted, all the reagents were purchased at their highest available qualities and used as received. 


\section{Protein expression and purification}

All the bacterial strains, plasmids, and primers used in this work are shown in Table 1. Shewanella oneidensis MR-1 was a gift from Dr. Jeffrey Gralnick of the University of Minnesota. VIBHAR_01913 (Vibrio harveyi, BB120, ATCC BAA-1116) WT and its mutants were expressed then purified with methods published previously [31]. PCR was used to amplify VP1876 with Phusion High-Fidelity DNA Polymerase (New England Biolabs) from Vibrio parahaemolyticus genomic DNA (Vibrio parahaemolyticus, EB101, ATCC 17802). Upstream and downstream primers contained NdeI and XhoI restrictions sites, respectively. SO_2145 was amplified by PCR from Shewanella oneidensis genomic DNA (Shewanella oneidensis, MR-1) with Phusion High-Fidelity DNA Polymerase. Upstream and downstream primers contained restriction sites EcoRI and XhoI, respectively. PCR was used to amplify lpg0278 with Phusion High-Fidelity DNA Polymerase from genomic DNA (Legionella pneumophila, subsp. Pneumophila str. Philadelphia 1). Upstream and downstream primers contained restriction sites NdeI and XhoI, respectively. Amplified VIBHAR_01913, VP1876 and SO2145 were cloned into expression vector pET-23aHis-TEV to yield N-terminus $6 \times$ His tagged plasmids. Amplified $\operatorname{lpg} 0278$ was cloned into pET-20b(+) to yield C-terminus $6 \times$ His-tagged plasmid. Cloned PCR products were transformed into $E$. coli $\mathrm{DH} 5 \alpha$ and positive transformants were verified by sequencing (Stony Brook DNA sequencing facility). Site directed mutagenesis was carried out to

make the VIBHAR_01913 D459A and VP1876 D499A mutant constructs following the QuikChange protocol from Stratagene. 
All proteins were expressed and purified as follows. Inserts containing plasmids were transformed into E. coli BL21(DE3)pLysS. Cells were grown in 2XYT media (16 g/L Tryptone, $10 \mathrm{~g} / \mathrm{L}$ yeast extract and $5 \mathrm{~g} / \mathrm{L} \mathrm{NaCl}$ ), supplemented with $100 \mu \mathrm{g} / \mathrm{mL}$ ampicillin and $34 \mu \mathrm{g} / \mathrm{mL}$ chloramphenicol at $37{ }^{\circ} \mathrm{C}$ with agitation at $250 \mathrm{rpm}$ (New Brunswick Scientific, Innova 4230) until $A_{600 n m}$ reached 0.6-0.9. Protein expression was induced with $100 \mu \mathrm{M}$ IPTG for 15 hours at $16{ }^{\circ} \mathrm{C}$, then cells were harvested. Proteins containing a $6 \times$ His tag and were purified by Ni-NTA agarose. This single column yielded proteins that were at least $95 \%$ pure as estimated by Commassie-stained SDS-PAGE (sodium dodecyl polyacrylamide sulfate gels). Protein concentrations were determined by Bradford assay with bovine serum albumin as a standard [32].

\section{Phosho-His stability test}

$\left[\gamma_{-}{ }^{32} \mathrm{P}\right]-\mathrm{ATP}(6000 \mathrm{Ci} / \mathrm{mmol}, 10 \mathrm{mCi} / \mathrm{mL})$ was purchased from PerkinElmer Health Sciences Inc. All reactions were performed at room temperature. Histidine kinases $(10$ or $25 \mu \mathrm{M})$ were equilibrated in the reaction buffer $(40 \mathrm{mM}$ Tris-Cl, $150 \mathrm{mM} \mathrm{KCl,10 \%}$ glycerol, and $4 \mathrm{mM}$ $\mathrm{MgCl}_{2}$ at $\mathrm{pH}$ 8.0) at room temperature for five minutes before initiation of the reaction by the addition of the ATP $(2$ or $4 \mathrm{mM})$ with trace amount of $\left[\gamma_{-}{ }^{32} \mathrm{P}\right]$-ATP $(10 \mu \mathrm{Ci})$. Reactions were stopped with either $2.5 \times$ SDS loading dye $(0.13 \%$ bromophenol blue, $0.25 \mathrm{M}$ dithiothreitol, $25 \%$ Glycerol, 5\% sodium dodecyl sulfate, $0.13 \mathrm{M}$ Tris- $\mathrm{HCl}$ at $\mathrm{pH}$ 6.8), for PAGE assays, or ice cold $5.77 \mathrm{mM}$ phosphoric acid, for filter paper-binding assays. Reactions quenched with phosphoric acid were kept on ice and then neutralized with $2.5 \times$ SDS loading dye at various time points to assess the effect of acid exposure.

\section{Phospho-His visualization}


Proteins were separated by electrophoresis on sodium dodecyl polyacrylamide sulfate gels (SDSPAGE). Ten microliters of quenched reactions, without boiling, were loaded onto a $12.5 \%$ sodium dodecyl sulfate (SDS) polyacrylamide gel. Proteins were separated by electrophoresis at $140 \mathrm{~V}$ for $80 \mathrm{~min}$. The resulting chromatogram was fixed (30\% methanol and $5 \%$ glycerol) for $30 \mathrm{~min}$, then stained (10\% acetic acid, 45\% methanol and $0.25 \mathrm{~g} / 100 \mathrm{~mL}$ Coomassie Brilliant Blue), followed by destaining (10\% acetic acid and 20\% methanol), and then dried (Promega Gel Drying kit V7120/7131). Dried gels were exposed to a storage phosphor-imaging screen (Molecular Dynamics) for 24 to 48 hours and images were scanned with the Typhoon scanner (Typhoon 9400, Amersham Biosciences). Band intensities from scanned images were quantified with image processing software ImageJ v1.46. Resulting band intensities were normalized to the band of a sample not exposed to phosphoric acid.

\section{Filter binding assay}

Whatman P81 ion exchange chromatography paper (catalog \# 21426-202) was purchased from VWR international. Histidine kinase activities were quantified with respect to time, enzyme concentration, and substrate concentration. In general, histidine kinases (10 or $25 \mu \mathrm{M})$ were equilibrated in the reaction buffer $(40 \mathrm{mM}$ Tris-Cl, $150 \mathrm{mM} \mathrm{KCl,10 \%}$ glycerol, and $4 \mathrm{mM}$ $\mathrm{MgCl}_{2}$ at $\mathrm{pH} \mathrm{8.0)}$ at room temperature for five minutes before initiation of the reaction by the addition of ATP $(2$ or $4 \mathrm{mM})$ with trace amount of $\left[\gamma_{-}^{32} \mathrm{P}\right]$-ATP $(10 \mu \mathrm{Ci})$. Reactions were stopped with ice-cold $5.77 \mathrm{mM}$ phosphoric acid and then were spotted onto Whatman P81 chromatography paper. The chromatography paper was immediately dropped into a container containing ice-cold $5.77 \mathrm{mM}$ phosphoric acid (10 mL/paper). The spotted chromatography papers were then washed by rocking on a benchtop rotator ( $25 \mathrm{rpm}$ ) for 10 minutes. The acid was 
replaced anew and washed two to three more times until no radioactivity was detected from the wash solution by a Geiger counter. After the wash, chromatography papers were rinsed briefly with acetone then air dried for 1 hour. The ${ }^{32} \mathrm{P}$ content of the dried chromatography papers was quantified in a liquid scintillation spectrometer (PerkinElmer, Tri-Carb 2900TR), without the addition of water or scintillation fluid. The specific activity of ATP solutions were determined from the radioactivity of the $\left[\gamma^{32}{ }^{32} \mathrm{P}\right]$-ATP solutions relative to amount of unlabeled ATP in the reaction. The resulting values were used to quantify enzyme specific activities. Dependence of autophosphorylation on reaction time and enzyme concentration were determined by stopping the reaction at different time points $(1-150 \mathrm{~min})$ or by conducting reactions with varying enzyme concentrations $(5-80 \mu \mathrm{M})$. These data were used to determined reaction times and enzyme concentrations that were within the linear range for use in monitoring the dependence of enzyme activity on substrate concentration.

\section{Data fitting and determination of kinetic parameters}

Data obtained from experiments with varying ATP concentrations, under conditions with which pHis formation was linear with respect to time and enzyme concentration, were fitted to the Michaelis-Menten model by use of KaleidaGraph software to determine $\mathrm{V}_{\max }, \mathrm{K}_{\mathrm{m}}$ and $k_{\text {cat }} / \mathrm{K}_{\mathrm{m}}$ values.

\section{RESULTS AND DISCUSSION}

TCS is a primary mechanism used by bacteria for adaptive responses to changes in their environment. TCS pathways are critically important in pathogenesis, as well as many other aspects of bacterial responses to changes in their environments [33,34]. Enzyme kinetic analyses 
have proven to be essential for understanding signal transduction in many different signaling pathways in many different organisms, both for fundamental characterization of these signaling pathways, as well as in drug discovery efforts $[35,36,37,38]$. Nonetheless, only a handful of bacterial HKs have been kinetically characterized. This is due in part to the lack of facile assay methods. Here we report the detailed kinetic parameters of several previously uncharacterized HKs as well as optimized conditions for detecting pHis using a medium-throughput filter paperbinding assay.

\section{Phospho-His stability}

Kinetic characterizations of HKs have primarily been accomplished by use of PAGE followed by autoradiography or alkali-based filter binding assays, but both of these assays have critical shortcomings. The PAGE/autoradiography method is labor intensive, time consuming, and has a small sample capacity. The alkali-based filter binding assay frequently suffers from considerable background [39]. In search of a rapid and efficient HK kinase activity quantification method, we revisited an acid-based filter binding assay $[40,41]$ and optimized the experimental conditions to overcome the inherent acid lability of pHis. We employed phosphoric acid at moderate concentration (final concentration, $5.77 \mathrm{mM}$ ) both to stop the phosphorylation reaction and to wash away unreacted ATP. We used this phosphoric acid concentration, because we found this to be enough acid to stop the reaction with minimal pHis cleavage. Furthermore, samples were kept near freezing during quenching and washing to avoid pHis degradation.

We used this assay to characterize kinetic behavior of four histidine kinases [ $V$. harveyi (gene ID: 5555316), V. parahaemolyticus (gene ID: 1189383), S. oneidensis (gene ID: 1169886), and L. 
pneumophila (gene ID: 19831845)]. S. oneidensis and L. pneumophila HKs are orthodox HKs that lack receiver domains. HKs from $V$. harveyi and $V$. parahaemolyticus are hybrid histidine kinases with receiver domains. We used receiver domain-aspartate mutant constructs of the hybrid $V h$ and $V p$ kinases (D459A and D499A, respectively), to ensure measurement of the autophosphorylation kinetics without interference from phosphotransfer and/or autophosphatase activities. As such, for each kinase in this study, we report kinetics determined by measuring the pHis autophosphorylated product. To establish the stability of pHis under our experimental conditions, each HK was incubated with ATP $/\left[\gamma_{-}{ }^{32} \mathrm{P}\right]-\mathrm{ATP}$ for $60 \mathrm{~min}$, and then phosphorylated HKs were incubated in ice-cold phosphoric acid. Samples were subjected to SDS-PAGE and the degradation of pHis over time was measured by autoradiography of the gels. All four HK tested in these experiments showed no measurable degradation of pHis upon exposure to ice-cold phosphoric acid (5.77 $\mathrm{mM}$, final concentration) for up to $60 \mathrm{~min}$ (Figure 1). This was very encouraging, as it is widely accepted that pHis is acid-labile; [23,25] however, our results indicate that pHis degradation is negligible at a moderate acid concentration in solution near the freezing point of water.

To further characterize the extent of pHis stability in our assay, the phosphorylation state of the HK from S. oneidensis was monitored over a $2 \mathrm{~h}$ incubation period in ice-cold phosphoric acid. Consistent with the earlier experiment, we observed no degradation of pHis up to $60 \mathrm{~min}$, followed by gradual degradation over the next 60 min. Overall, we observed a $7 \%$ reduction in phosphorylation of $\mathrm{SoHK}$ after 90 min of incubation in acid and a $21 \%$ reduction after $120 \mathrm{~min}$ of acid-incubation. In subsequent experiments, all of the enzymes reported here were exposed to acid for no more than 60 min over the course of reaction quenching, filter paper binding, and 
successive washing steps. Therefore, we conclude that under our reported conditions, the integrity of pHis protein phosphorylation is maintained.

\section{Effect of time and enzyme concentration}

To allow an accurate assessment of the kinetic parameters of each HK enzyme studied here, the linear range of $\mathrm{HK}$ enzyme activity, as a function of time and enzyme concentration, was determined. HKs were incubated with ATP with trace $\left[\gamma_{-}{ }^{32} \mathrm{P}\right]-\mathrm{ATP}$, and at various time points the phosphorylated HKs were subjected to ice-cold phosphoric acid to stop the reaction. As illustrated in Figure 2, plots of phosphorylation as a function of time, for all four HKs tested here, showed the expected enzyme saturation curves, with reactions reaching saturation between 15 $\min ($ L. pneumophila) and $100 \mathrm{~min}$ (V. harveyi). The linear range of the autophosphorylation reaction with respect to time was determined from these plots [41]. To determine the linear range of the $\mathrm{HK}$ autophosphorylation activity as a function of enzyme concentration, pHis formation at varying enzyme concentrations was measured with fixed incubation time (40 min for $V$. harveyi, $20 \mathrm{~min}$ for $V$. parahaemolyticus, $5 \mathrm{~min}$ for $S$. oneidensis and $1 \mathrm{~min}$ for L. pneumophila) and ATP concentration (2 $\mathrm{mM}$ ) (Figure 3). As expected, product formation increased linearly as a function of enzyme concentrations for all HKs tested at the given reaction times and substrate concentrations

\section{Substrate kinetics}

Finally, in order to determine the $k_{\text {cat }}$ and $\mathrm{K}_{\mathrm{m}}$ for each $\mathrm{HK}$, pHis formation as a function of ATP concentration was measured for each HK. Incubation time and enzyme concentration for each HK was chosen based on the results of the time- and enzyme-dependent reactions described 
above (Figures 2 and 3). As illustrated in Figure 4, all four HKs showed the expected linear double reciprocal plot with increasing ATP concentration. Data were fitted to the MichaelisMenten model to determine the kinetic parameters. The kinetic parameters for each HK studied here, as well as those of previously characterized HKs, are summarized in Table 2.

Kinetic constants for the kinases from V. parahaemolyticus, S. oneidensis, and L. pneumophila are reasonably similar to those of many previously characterized E. coli HKs (Table 2). In our hands $V$. harveyi $\mathrm{HK}$ exhibited a relatively low catalytic efficiency $\left(0.02 \mathrm{M}^{-1} \mathrm{sec}^{-1}\right)$ and a large $\mathrm{K}_{\mathrm{m}}(2.26 \mathrm{mM})$. The reasons for the high $\mathrm{K}_{\mathrm{m}}$ and low catalytic efficiency remain unclear. However, since $V h \mathrm{HK}$ is a dual-functioning enzyme, with both kinase and phosphatase activities ENREF 8[8], it is conceivable that the primary function of this enzyme may be as a phosphatase. It is also possible that the autophosphorylation activity of $V h \mathrm{HK}$ may be enhanced upon detection of a ligand through its partner sensory protein.

The method described in this paper provides an optimized protocol for analyzing the autophosphorylation activity of histidine kinases. The most commonly used PAGE-based method for analysis of HK-autophosphorylation is labor intensive, limits the sample number, and is time consuming. Our method is facile; it is less labor-intensive and allows a researcher to process a large number of samples in a short period of time, without risking degradation of pHis. This method proved to be effective for determining the kinetic parameters of four previously uncharacterized HKs. We propose that this assay can be used to determine the rate of autophosphorylation of any HK and may be applied further to determine the effect of ligands on HK kinase activity. 


\section{ACKNOWLEDGEMENTS}

We gratefully acknowledge Stony Brook University and the Office of Naval Research for financially supporting this work (award N00014-10-1-0099 to E.M.B.). We thank Dr. Jeffrey Gralnick of the University of Minnesota for generously providing Shewanella oneidensis MR-1. 


\section{REFERENCES}

[1] A.M. Stock, V.L. Robinson, P.N. Goudreau, Two-component signal transduction, Annual Review of Biochemistry 69 (2000) 183-215.

[2] T. Krell, J. Lacal, A. Busch, H. Silva-Jimenez, M.-E. Guazzaroni, J.L. Ramos, Bacterial sensor kinases: diversity in the recognition of environmental signals, Annual Review of Microbiology (2010) 539-559.

[3] K. Jung, L. Fried, S. Behr, R. Heermann, Histidine kinases and response regulators in networks, Current Opinion in Microbiology 15 (2012) 118-124.

[4] R.C. Stewart, Protein histidine kinases: assembly of active sites and their regulation in signaling pathways, Current Opinion in Microbiology 13 (2010) 133-141.

[5] J.S. Parkinson, E.C. Kofoid, Communication Modules in Bacterial Signaling Proteins, Annual Review of Genetics 26 (1992) 71-112.

[6] B.T. Nixon, C.W. Ronson, F.M. Ausubel, Two-component regulatory systems responsive to environmental stimuli share strongly conserved domains with the nitrogen assimilation regulatory genes ntrB and ntrC, Proceedings of the National Academy of Sciences 83 (1986) $7850-7854$.

[7] C.W. Ronson, T. Nixon, F.M. Ausubel, Conserved domains in bacterial regulatory proteins that respond to environmental stimuli, Cell 49 (1987) 579-581.

[8] A.J. Ninfa, B. Magasanik, Covalent modification of the ginG product, NRI, by the glnL product, NRII, regulates the transcription of the glnALG operon in Escherichia coli, Proceedings of the National Academy of Sciences of the United States of America 83 (1986) 5909-5959. 
[9] I.B. Zhulin, The superfamily of chemotaxis transducers: from physiology to genomics and back., Advances in Microbial Physiology 45 (2001) 157-198.

[10] K. Ishige, S. Nagasawa, S.-i. Tokishita, T. Mizunol, A novel device of bacterial signal transducers, The EMBO Journal 13 (1994) 5195-5202.

[11] M.A. Uhl, J.F. Miller, Integration of multiple domains in a two-component sensor protein: the Bordetella pertussis BvgAS phosphorelay., The EMBO Journal 15 (1996) 1028.

[12] A. Rodrigue, Y. Quentin, A. Lazdunski, V. Mejean, M. Foglino, Two-component systems in Pseudomonas aeruginosa: why so many?, Trends Microbiol 8 (2000) 498-504.

[13] V.L. Robinson, D.R. Buckler, A.M. Stock, A tale of two components: a novel kinase and a regulatory switch, Nature Structural Biology 7 (2000) 626-633.

[14] T. Mizuno, Compilation of All Genes Encoding Two-component Phosphotransfer Signal Transducers in the Genome of Escherichia coli DNA Research 4 (1997) 161-168.

[15] J.A. Freeman, B.L. Bassler, A genetic analysis of the function of LuxO, a two-component response regulator involved in quorum sensing in Vibrio harveyi, Molecular Microbiology 31 (1999) 665-677.

[16] F.J. Hess, R.B. Bourret, M.I. Simon, Phosphorylation assays for proteins of the twocomponent regulatory system controlling chemotaxis in Escherichia coli., Methods in Enzymology 200 (1991) 188-204.

[17] Y.-F. Wei, J.E. Morgan, H.R. Matthews, Studies of histidine phosphorylation by a nuclear protein histidine kinase show that histidine-75 in histone $\mathrm{H} 4$ is masked in nucleosome core particles and in chromatin., Archives of Biochemistry and Biophysics 268 (1989) 546-550. 
[18] A. Marina, C. Mott, A. Auyzenberg, W.A. Hendrickson, C.D. Waldburger, Structural and mutational analysis of the PhoQ histidine kinase catalytic domain. Insight into the reaction mechanism, The Journal of Biological Chemistry 276 (2001) 41182-41190.

[19] P. Tawa, R.C. Stewart, Kinetics of CheA autophosphorylation and dephosphorylation reactions, Biochemistry 33 (1994) 7917-7924.

[20] C. Grimshaw, S. Huang, C. Hanstein, M. Strauch, D. Burbulys, L. Wang, J. Hoch, J. Whiteley, Synergistic kinetic interactions between components of the phosphorelay controlling sporulation in Bacillus subtilis, Biochemistry 37 (1998) 1365-1375.

[21] D.E. Hultquist, R.W. Moyer, P.D. Boyer, The Preparation and Characterization of 1Phosphohistidine and 3-Phosphohistidine, Biochemistry 5 (1966) 322-331.

[22] D.E. Hultquist, The preparation and characterization of phosphorylated derivatives of histidine, Biochimica et Biophysica Acta 153 (1968) 329-340.

[23] P.V. Attwood, M.J. Piggott, X.L. Zu, P.G. Besant, Focus on phosphohistidine, Amino Acids (2007) 145-156.

[24] B. Duclos, S. Marcandier, A.J. Cozzone, Chemical properties and separation of phosphoaminoacids by thin-layer chromatography and/or electrophoresis, Methods Enzymol (1991) 10-21.

[25] J.-M. Kee, T.W. Muir, Chasing phosphohistidine, an elusive sibling in the phosphoamino acid family, ACS Chem Biol 7 (2012) 44-51.

[26] H.K. Carlson, L. Plate, M.S. Price, J.J. Allen, K.M. Shokat, M.A. Marletta, Use of a semisynthetic epitope to probe histidine kinase activity and regulation, Anal Biochem 397 (2010) 139-143. 
[27] J.-M. Kee, R.C. Oslund, D.H. Perlman, T.W. Muir, A pan-specific antibody for direct detection of protein histidine phosphorylation, Nature Chemical Biology 9 (2013) 416421.

[28] L.J. Kenney, Kinase activity of EnvZ, an osmoregulatory signal transducing protein of Escherichia coli, Arch Biochem Biophys 346 (1997) 303-311.

[29] C.E. Noriega, R. Schmidt, M.J. Gray, L.-L. Chen, V. Stewart, Autophosphorylation and dephosphorylation by soluble forms of the nitrate-responsive sensors NarX and NarQ from Escherichia coli K-12, J. Bacteriol (2008) 3869-3876.

[30] P. Jiang, J.A. Peliska, A.J. Ninfa, Asymmetry in the Autophosphorylation of the TwoComponent Regulatory System Transmitter Protein Nitrogen Regulator II of Escherichia coli, Biochemistry 39 (2000) 5057-5065.

[31] B.M. Henares, K.E. Higgins, E.M. Boon, Discovery of a nitric oxide responsive quorum sensing circuit in Vibrio harveyi, ACS Chem Biol 7 (2012) 1331-1336.

[32] M.M. Bradford, A rapid and sensitive method for the quantitation of microgram quantities of protein utilizing the principle of protein-dye binding, Analytical Biochemistry (1976) 248-254.

[33] S.I. Miller, A.M. Kukral, J.J. Mekalanos, A two-component regulatory system (phoP phoQ) controls Salmonella typhimurium virulence, Proceedings of the National Academy of Sciences of the United States of America 86 (1989).

[34] M. Kasahara, A. Nakata, H. Shinagawa, Molecular Analysis of the Escherichia coli phoPphoQ Operon, Journal of Bacteriology 174 (1992) 492-498. 
[35] A. Samuele, E. Crespan, A. Garbelli, L. Bavagnoli, G. Maga, The power of enzyme kinetics in the drug development process, Current Pharmaceutical Biotechnology 14 (2013) 551560.

[36] B.D. Brooks, A.E. Brooks, Therapeutic strategies to combat antibiotic resistance, Advanced Drug Delivery Reviews 78 (2014) 14-27.

[37] Z. Wang, P.A. Cole, Catalytic Mechanisms and Regulation of Protein Kinases, Methods in Enzymology 548 (2014) 1-21.

[38] H. Nishi, A. Shaytan, A.R. Panchenko, Physicochemical mechanisms of protein regulation by phosphorylation, Frontiers in Genetics 5 (2014) 1-10.

[39] Y.-F. Wei, H.R. Matthews, A filter-based protein kinase assay selective for alkali-stable protein phosphorylation and suitable for acid-labile protein phosphorylation, Analytical Biochemistry 190 (1990) 188-192.

[40] H.R. Matthews, Protein kinases and phosphatases that act on histidine, lysine, or arginine residues in eukaryotic proteins: a possible regulator of the mitogen-activated protein kinase cascade, pharmacology \& Therapeutics 67 (1995) 323-350.

[41] M.R. El-Maghrabi, J.J. Correia, P.J. Heil, T.M. Pate, C.E. Cobb, S.J. Pilkis, Tissue distribution, immunoreactivity, and physical properties of 6-phosphofructo-2kinase/fructose-2,6-bisphosphatase, Proceedings of the National Academy of Sciences 83 (1986) 5005-5009. 


\section{FIGURE CAPTIONS}

Figure 1. Stability of pHis on HKs from $V$. harveyi (A), V. parahaemolyticus (B), S. oneidensis (C), and L. pneumophila (D) pHis. The reaction mixture contained $40 \mathrm{mM}$ Tris-Cl, $150 \mathrm{mM} \mathrm{KCl}$, $10 \%$ glycerol and $4 \mathrm{mM} \mathrm{MgCl} 2$ at $\mathrm{pH}$ 8.0. Histidine kinase and ATP concentrations respectively, were $10 \mu \mathrm{M}$ and $2 \mathrm{mM}$ for $V$. harveyi, $25 \mu \mathrm{M}$ and $2 \mathrm{mM}$ for $V$. parahaemolyticus, $22 \mu \mathrm{M}$ and 2 $\mathrm{mM}$ for $S$. oneidensis, and $16 \mu \mathrm{M}$ and $2.5 \mathrm{mM}$ for L. pneumophila. Autoradiography of PAGE gels showed phosphorylated histidine kinases after exposure to ice-cold $5.77 \mathrm{mM}$ phosphoric acid for the amount of time indicated. Band intensities were quantified using ImageJ. No measurable degradation was observed within $60 \mathrm{~min}$ for any HK tested. Phosphorylated $S$. oneidensis (panel C) was exposed to these acidic conditions for an additional 60 minutes, during which gradual degradation was observed: $7 \%$ degradation at $90 \mathrm{~min}$ and $21 \%$ degradation at 120 $\min$.

Figure 2. Time-dependent autophosphorylation of $\mathrm{HKs}$ from $V$. harveyi (A), $\quad V$. parahaemolyticus (B), S. oneidensis (C), and L. pneumophila (D). Reactions were carried out at $23{ }^{\circ} \mathrm{C} \pm 1{ }^{\circ} \mathrm{C}$. ATP concentrations and enzyme concentrations, respectively, were $2.1 \mathrm{mM}$ and 16 $\mu \mathrm{M}$ for $V$. harveyi, $2.1 \mathrm{mM}$ and $14 \mu \mathrm{M}$ for $V$. parahaemolyticus, $2.1 \mathrm{mM}$ and $14 \mu \mathrm{M}$ for $S$. oneidensis, and $2.1 \mathrm{mM}$ and $50 \mu \mathrm{M}$ for L. pneumophila. Product formation was monitored over time by use of the filter-binding assay described in under Materials and Methods. All four tested HKs showed saturation curves in a time dependent manner. Reactions reach saturation within 15 to $100 \mathrm{~min}$. 
Figure 3. Enzyme concentration-dependent autophosphorylation of HKs from $V$. harveyi (A), $V$. parahaemolyticus (B), S. oneidensis (C), and L. pneumophila (D). ATP concentrations and incubation times were $2 \mathrm{mM}$ and $40 \mathrm{~min}$ for $V$. harveyi, $2 \mathrm{mM}$ and $20 \mathrm{~min}$ for $V$. parahaemolyticus, $2 \mathrm{mM}$ and $5 \mathrm{~min}$ for S. oneidensis, and $2 \mathrm{mM}$ and $1 \mathrm{~min}$ for L. pneumophila. Reactions were carried out at $23{ }^{\circ} \mathrm{C} \pm 1{ }^{\circ} \mathrm{C}$.

Figure 4. Substrate concentration-dependent autophosphorylation of HKs from $V$. harveyi (A), $V$. parahaemolyticus (B), S. oneidensis (C), and L. pneumophila (D). Double reciprocal plots are shown. Reactions were carried out at $23{ }^{\circ} \mathrm{C} \pm 1{ }^{\circ} \mathrm{C}$. Enzyme concentrations and incubation times, respectively, were $35 \mu \mathrm{M}$ and $40 \mathrm{~min}$ for $V$. harveyi, $14 \mu \mathrm{M}$ and $20 \mathrm{~min}$ for $V$. parahaemolyticus, $18 \mu \mathrm{M}$ and $5 \mathrm{~min}$ for $S$. oneidensis, and $52 \mu \mathrm{M}$ and $1 \mathrm{~min}$ for L. pneumophila. Error bars represent the standard error of the mean from a minimum of three assays. 
Table 1. Bacterial strains, plasmids, and primers used in this work.

\begin{tabular}{|c|c|c|}
\hline Strains, plasmids and primers & Genotype & Reference \\
\hline \multicolumn{3}{|l|}{ Bacterial strains } \\
\hline \multicolumn{3}{|l|}{$V$. harveyi } \\
\hline WT & Vibrio harveyi, BB120, ATCC BAA-1116 & ATCC \\
\hline \multicolumn{3}{|l|}{$V$. parahaemolyticus } \\
\hline WT & Vibrio parahaemolyticus, EB101, ATCC 17802 & ATCC \\
\hline \multicolumn{3}{|l|}{ S. oneidensis } \\
\hline WT & Shewanella oneidensis, MR-1 & \\
\hline \multicolumn{3}{|l|}{ L. pneumophila } \\
\hline WT & Legionella pneumophilla, Philadelphia-1, ATCC 33152 & ATCC \\
\hline \multicolumn{3}{|c|}{ 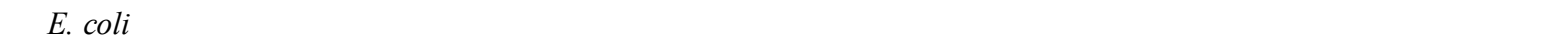 } \\
\hline $\mathrm{DH} 5 \alpha$ & Cloning competent cell & Invitrogen \\
\hline BL21(DE3)pLysS & Expression competent cell & Invitrogen \\
\hline \multicolumn{3}{|l|}{ Plasmids } \\
\hline pVh_HqsK(D459A) & pET-23aHis-Tev with VIBHAR_01913, N-terminus 6x His-tag, Amp ${ }^{r}$ & {$[28]$} \\
\hline pVp_HqsK(D499A) & pET-23aHis-Tev with VP1876, N-terminus 6x His-tag, Amp $^{r}$ & This work \\
\hline pSo_HK(WT) & pET-23aHis-Tev with SO_2145, N-terminus 6x His-tag, Amp ${ }^{\mathrm{r}}$ & This work \\
\hline pLp_HK(WT) & pET-20b(+) with lpg0278, C-terminus 6x His-tag, Amp ${ }^{r}$ & This work \\
\hline \multicolumn{3}{|c|}{, e } \\
\hline pVh_HqsK(WT)-Fwd & GCG AAT TCG TGG CGT TAA AGA AAC TCG & \\
\hline pVh_HqsK(WT)-Rvs & CAA TGA AGC TTT TCG CCG AGC CAT TTA CAC & \\
\hline pVp_HqsK(WT)-Fwd & GGA TCC ATA TGA TGA CGG GTA ACT CC & \\
\hline pVp_HqsK(WT)-Rvs & GCA TTC TCG AGC TAC TGC TCA AGC & \\
\hline pSO_HK(WT)-Fwd & CCA TCC GAA TTC ATG ACT GAC AGC GAA AAT CCC & \\
\hline pSO_HK(WT)-Rvs & CCA GCA GAG CTC CTA GGT TAT CGA GCT AGA AGT & \\
\hline pLp_HK(WT)-Fwd & NNN CAT ATG ACA GAA ATG CAT CGG TTG TTG CAG & \\
\hline pLp_HK(WT)-Rvs & NNN CTC GAG CCT CGT ACT CAA GGT TTT GGG ATT G & \\
\hline
\end{tabular}

Abbreviation: $\mathrm{Amp}^{\mathrm{r}}$ : Ampicillin resistance 
Table 2. Summary of histidine kinase autophosphorylation kinetic parameters for all characterized HK enzymes to date.

\begin{tabular}{|c|c|c|c|c|c|c|c|c|c|}
\hline Protein & \multicolumn{2}{|c|}{$\begin{array}{c}\mathbf{V}_{\max } \\
(\mathbf{n m o l} / \mathbf{m g} \cdot \min )\end{array}$} & \multicolumn{2}{|r|}{$\begin{array}{c}k_{\text {cat }} \\
(/ \mathbf{s e c})\end{array}$} & \multicolumn{3}{|c|}{$\begin{array}{c}\mathbf{K}_{\mathrm{m}} \\
(\boldsymbol{\mu M})\end{array}$} & \multirow{2}{*}{$\begin{array}{c}\boldsymbol{k}_{\text {cal }} / \mathbf{K}_{\mathrm{m}} \\
(/ \mathbf{M s e c})\end{array}$} & \multirow{2}{*}{$\begin{array}{c}\text { Ref. } \\
\text { This work }\end{array}$} \\
\hline V. harveyi $\mathrm{HK}$ & 0.050 & \pm 0.006 & $(4.95$ & $\pm 0.63) * 10^{-5}$ & 2260 & \pm & 340 & & \\
\hline V.parahaemolyticus $\mathrm{HK}$ & 0.056 & \pm 0.003 & $(6.01$ & $\pm 0.33) * 10^{-5}$ & 177 & \pm & 12 & 0.34 & This work \\
\hline S. oneidensis HK & 0.476 & \pm 0.032 & $(2.83$ & $\pm 0.19) * 10^{-4}$ & 88 & \pm & 14 & 3.23 & This work \\
\hline L. pneumophila $\mathrm{HK}$ & 1.320 & \pm 0.218 & $(1.18$ & $\pm 0.20) * 10^{-3}$ & 173 & \pm & 19 & 6.80 & This work \\
\hline E. coli, EnvZ & & - & 8.10 & $* 10^{-5}$ & 218 & & & 0.37 & {$[28]$} \\
\hline E. coli, NarQ & & - & $(2.20$ & $\pm 1.10) * 10^{-4}$ & 23 & \pm & & 9.65 & [29] \\
\hline B. subtilis, KinA & & - & $(1.90$ & $\pm 0.50) * 10^{-3}$ & 74 & \pm & 11 & 25.7 & {$[20]$} \\
\hline E. coli, CheA & & - & $(2.60$ & $\pm 0.40) * 10^{-2}$ & 770 & & & 33.8 & [19] \\
\hline E. coli, NRII (NtrB) & & - & $(2.37$ & $\pm 0.05) * 10^{-2}$ & 31 & \pm & 1 & 763.4 & {$[30]$} \\
\hline E. coli, $\mathrm{PhoQ}$ & & - & $(1.70$ & $\pm 0.81) * 10^{-3}$ & 21 & \pm & 13 & 81.2 & {$[18]$} \\
\hline
\end{tabular}


Figure 1

A.

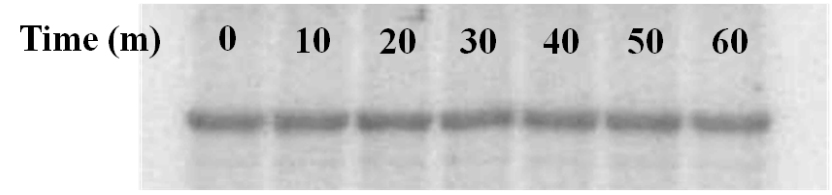

C.

$\begin{array}{llllllll}\text { Time (m) } & 0 & 10 & 20 & 30 & 60 & 90 & 120\end{array}$
B.

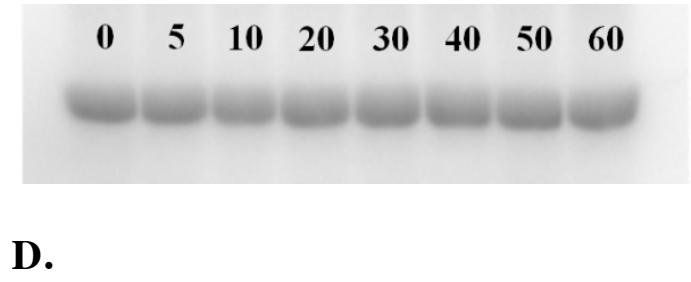


Figure 2

A.

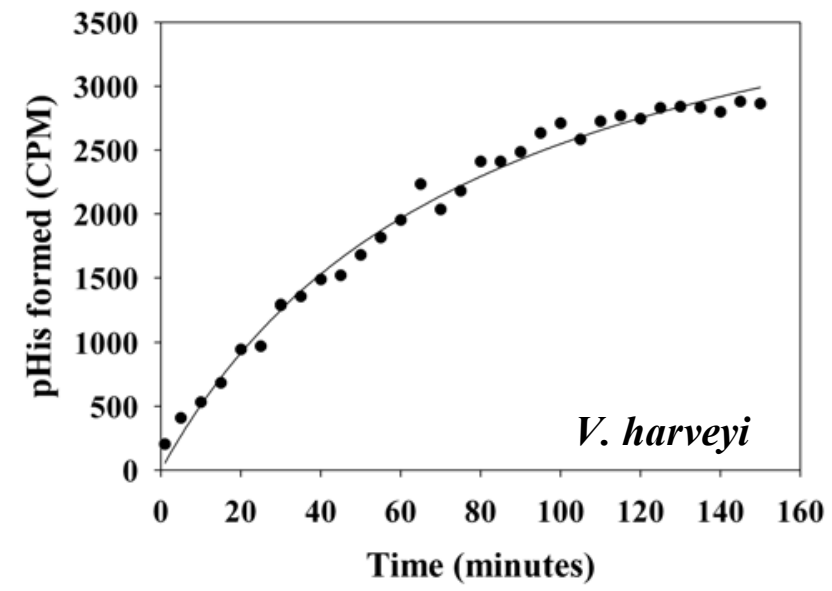

C.

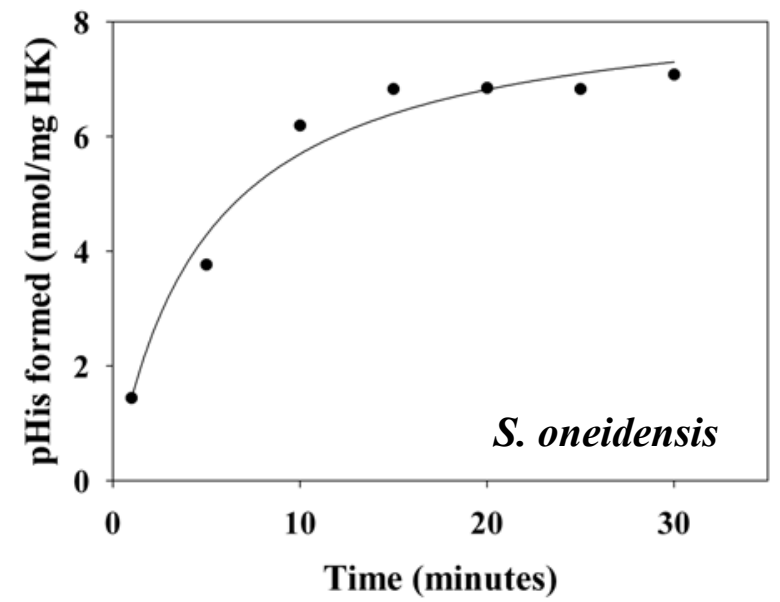

B.

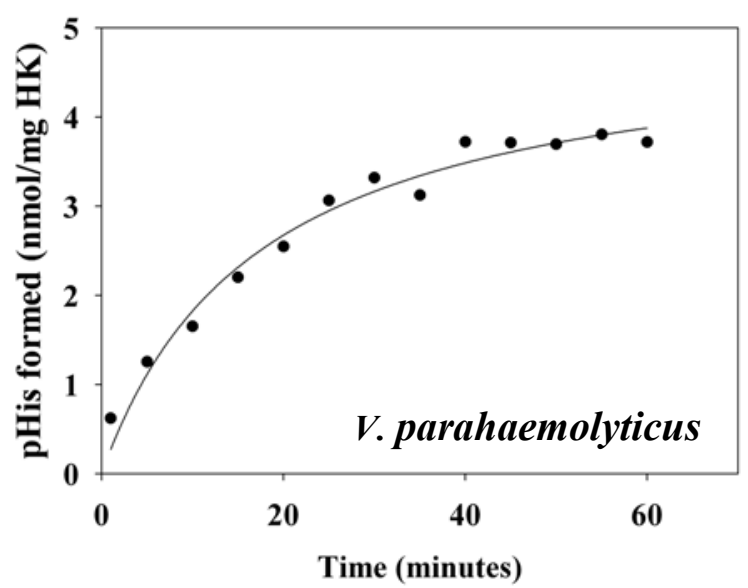

D.

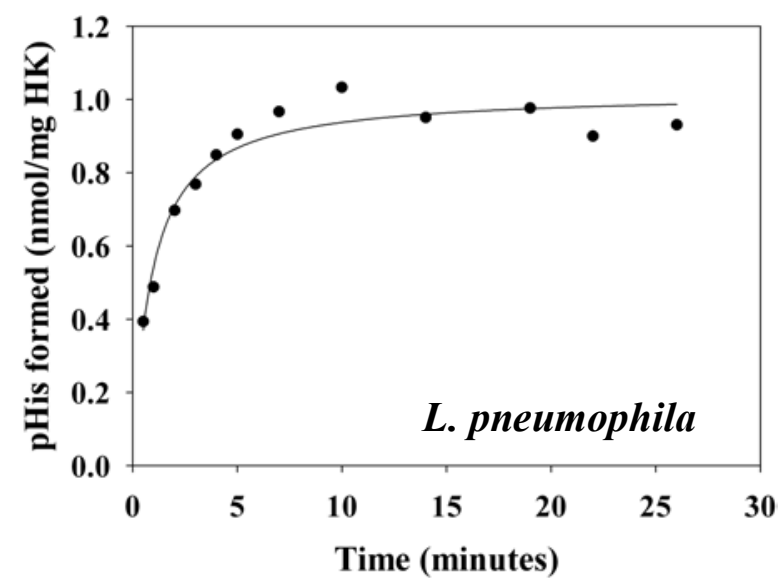


Figure 3

A.

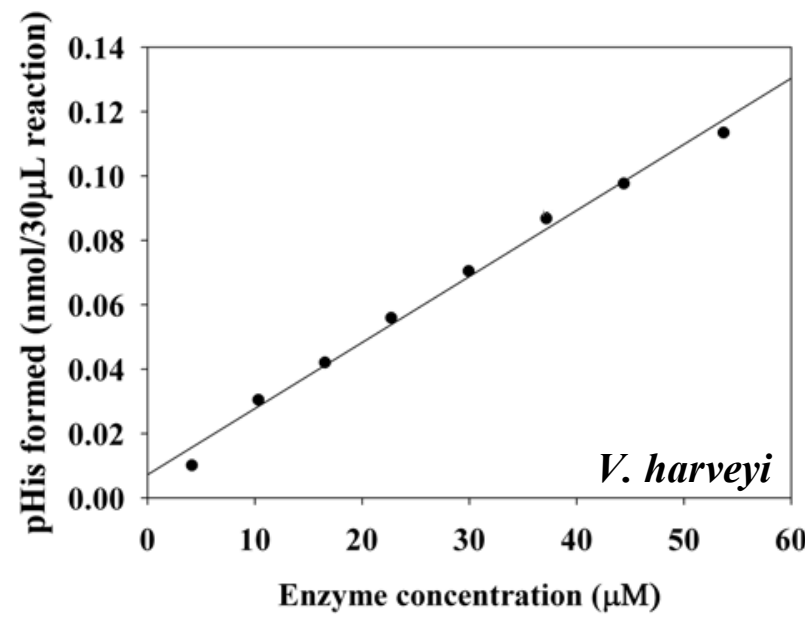

c.

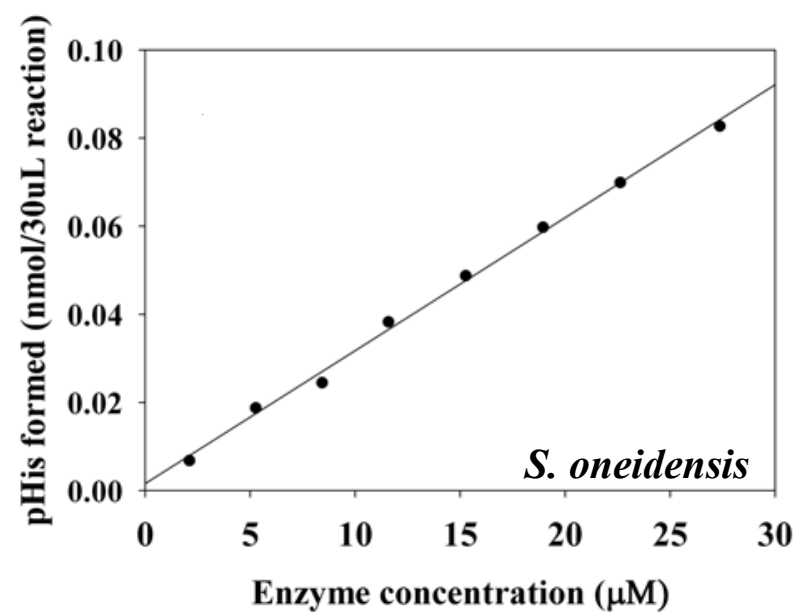

B.

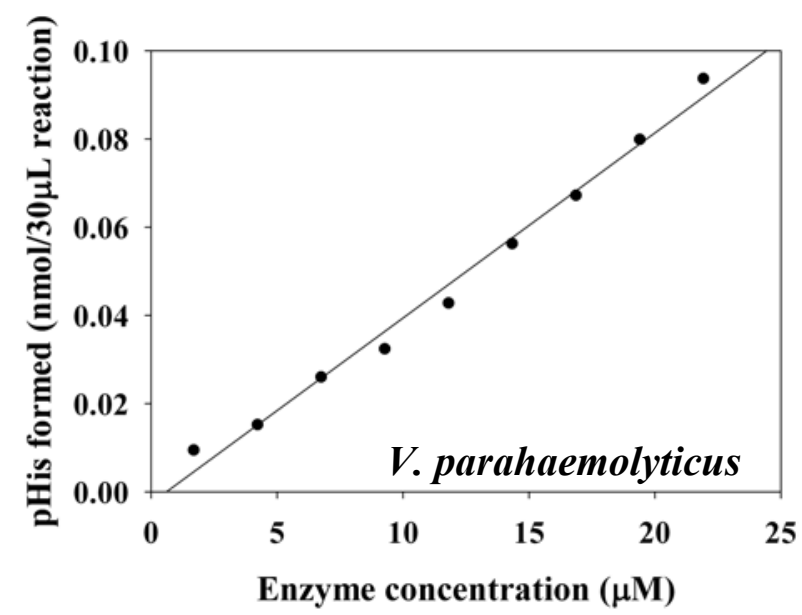

D.

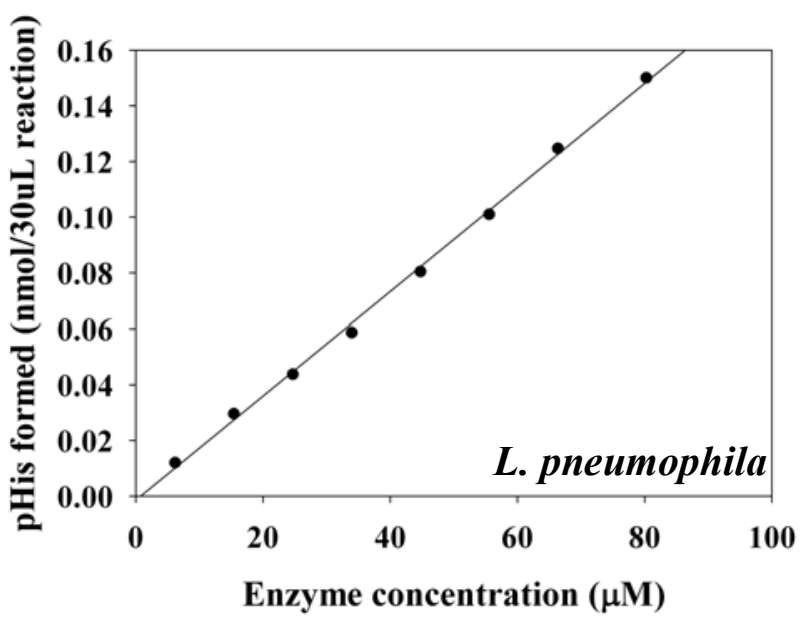


Figure 4

A.

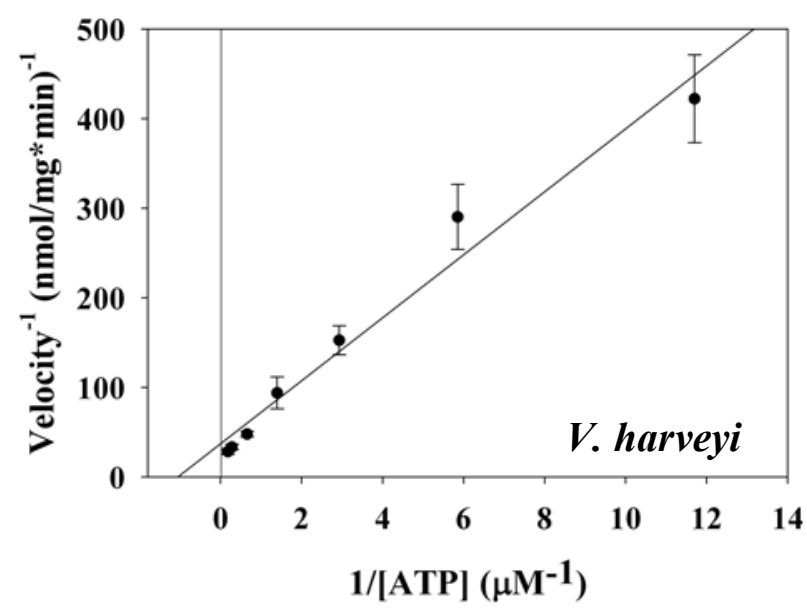

c.

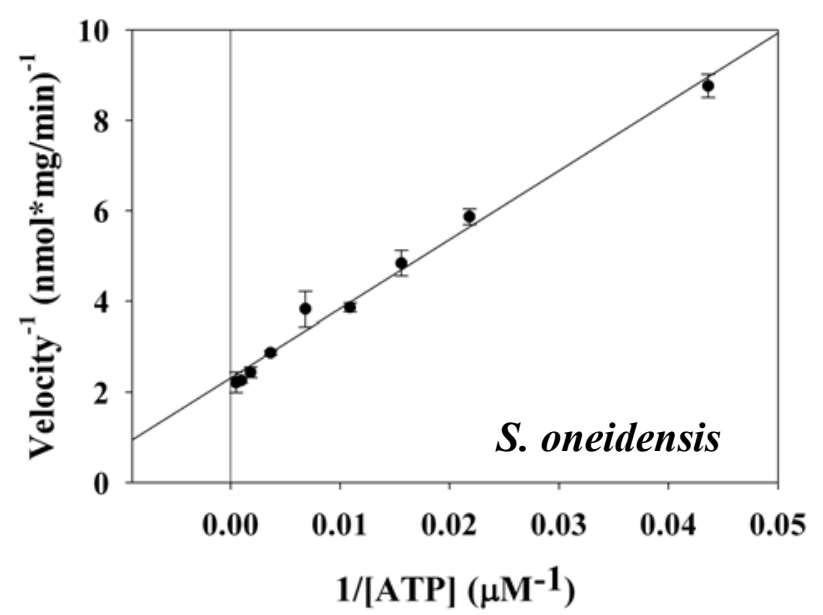

B.

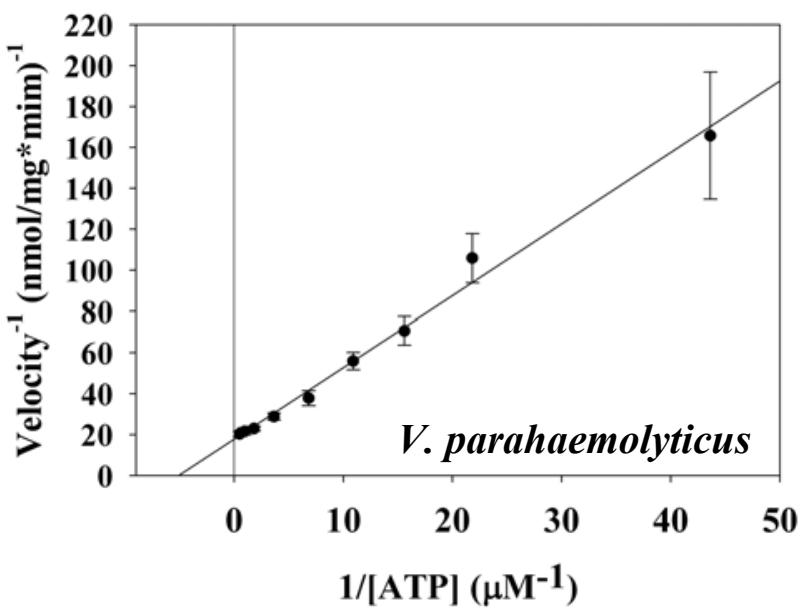

D.

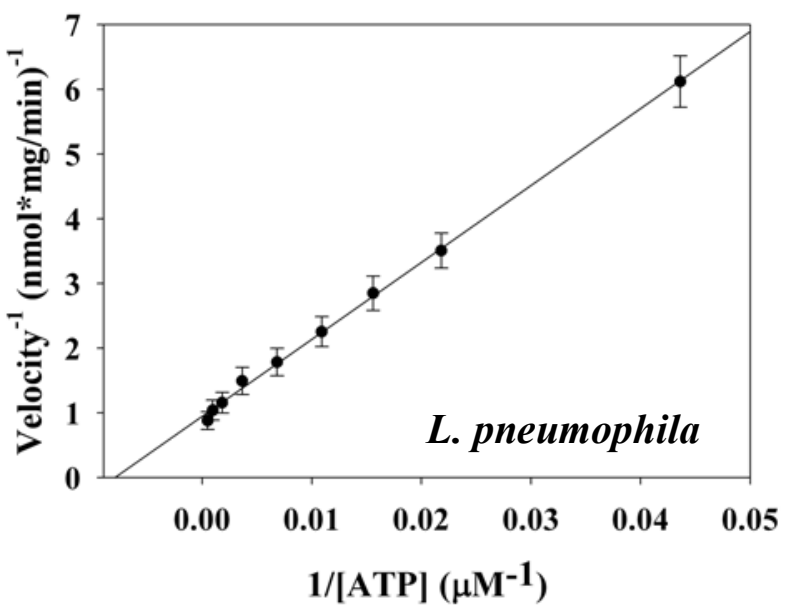

